\title{
Veganismo, violência sexual e insanidade na narrativa coreana contemporânea
}

\author{
Veganism, Sexual Violence and Insanity in Contemporary Korean Narrative
}

\author{
Anselmo Peres Alós ${ }^{1}$ (iD 0000-0003-2062-2096 \\ 'Universidade Federal de Santa Maria, Departamento de Letras Vernáculas, Santa \\ Maria, RS, Brasil.97105-115 - dlvcal@gmail.com / ppgletras@gmail.com.
}

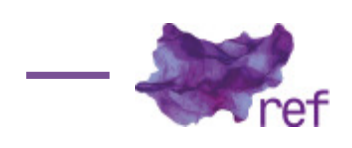

KANG, Han.

A vegetariana.

Trad. de Jae Hyung Woo. São Paulo: Todavia, 2018. 176p.

\begin{abstract}
A vegetariana, de Han Kang, foi publicado pela primeira vez, na Coréia do Sul, em 2007. Foi traduzido para o inglês por Deborah Smith e lançado em 2015 nos Estados Unidos, recebendo, em maio de 2016, o Man Booker Internacional Prize'. Mesmo já tendo recebido alguns prêmios quando publicado em sua língua original, foi o Man Booker International Prize que terminou por transformar a prosa de Han Kang em um fenômeno editorial contemporâneo. O romance já havia sido trazido para português anteriormente, em 2013, por Yun Jung Im, e publicado pela Editora Devir (192 páginas)². Essa tradução, entretanto, foi bastante criticada, e em 2018 a Editora Todavia, de São Paulo, lança uma nova edição, dessa vez com tradução realizada por Jae Hyung Woo.

Os três capítulos que constituem a obra podem ser lidos como os três momentos narrativos de um romance, ou então como três novelas independentes, todas tomando Yonghye Kim como a figura principal: "A vegetariana", narrada majoritariamente por Jeong (o marido de Yonghye Kim), com algumas intervenções da protagonista, marcadas em itálico; "A mancha mongólica", narrada em terceira pessoa, tendo como focalizador o cunhado de Yonghye Kim (aqui a voz Yonghye Kim aparece apenas em algumas poucas linhas, como discurso direto, em resposta a perguntas feitas pelo seu cunhado); e, finalmente, "Árvores em chamas", narrada em terceira pessoa, com Inhye Kim (irmã mais velha de Yonghye Kim, ex-esposa do narrador do segundo capítulo/novela³) como focalizadora. Essa breve descrição já chama a atenção para aquele que talvez seja um dos pontos fundamentais a interligar as três narrativas: o fato de que Yonghye Kim é sempre tratada como objeto da narração de uma voz narrativa que sempre se apresenta soberana, em um registro narrativo homodiegético.

Nas três narrativas de A vegetariana, é apresentada a história de Yonghye Kim, uma dona de casa que subitamente decide parar de comer e consumir produtos de origem animal em função de uma série de pesadelos envolvendo matanças que a perturbam ao longo das noites.

' KANG, Han. The vegetarian. Translated by Deborah Smith. London: Porto Belo Books, 2016.

2 KANG, Han. A vegetariana. Trad. de Yun Jung Im. São Paulo: Devir, 2013.

${ }^{3}$ A partir daqui, considerarei cada "capítulo/novela" simplesmente como uma narrativa que integra o livro $A$ vegetariana, já que não interessa aqui o status literário de cada uma dessa narrativas (que podem ser consideradas tanto como capítulos de um romance quanto como novelas ou contos independentes).
\end{abstract}


Sua abstinência ao consumo de produtos de origem animal aliena-a paulatinamente do contato com o marido, com a família e com a sociedade coreana. Na primeira narrativa, "A vegetariana", Jeong narra com estranhamento o processo abrupto que leva sua esposa a parar de consumir carne. Após alguns meses tentando compreender a mudança de hábitos da esposa, Jeong conversa com a família da esposa e solicita uma intervenção. Sentados todos em volta da mesa, a família leva a cabo múltiplas tentativas crescentemente violentas de tentar convencer Yonghye Kim a comer carne, e falha em todas elas. O ápice da cena ocorre quando o pai de Yonghye Kim bruscamente levanta-se, estapeia a filha e enfia um pedaço de carne de porco na boca da filha, tentando forçá-la a engolir. Em resposta à violência do pai, Yonghye Kim grita, cospe o pedaço de carne de porco e enfia uma faca no próprio pulso. Cada vez mais incapaz de conviver com os hábitos de Yonghye Kim, que são vistos pela família como extravagâncias muito fora do escopo da razoabilidade e da sensatez, a família interna Yonghye Kim em um manicômio.

Ademais das três violências em torno das quais cada uma das narrativas é construída (o carnivorismo e a opressão das mulheres em "A vegetariana"; a objetificação do corpo feminino e a violência sexual em "A mancha mongólica"; e, finalmente, a violência institucional, o encarceramento e a objetificação do sujeito em função dos "regimes de sanidade" em "Árvores em chamas"), um outro registro da violência merece destaque: a violência perpetrada contra Yonghye Kim pela própria voz narrativa das três novelas, que sistematicamente objetificam a personagem e lhe subtraem a possibilidade de narrar a si mesma (isto é, de contar a sua própria história através de sua própria perspectiva). Em "A vegetariana", a narração acontece em primeira pessoa, enquanto que em "A mancha mongólica" e em "Árvores em chamas" a narração acontece em terceira pessoa. Todavia, isso não é relevante; o que é relevante aqui é que a focalização é sempre dada por um outro personagem que não Yonghye Kim, o que a transforma em objeto da voz narrativa, e não em sujeito de sua própria enunciação - conferir, a esse respeito, Mieke Bal $(1994 ; 1996 ; 1997)$.

O vegetarianismo da protagonista (talvez fosse mais justo falar em "veganismo", já que ela se desfaz até mesmo dos sapatos de couro que possui) leva-a a um crescente isolamento e incomunicabilidade com o mundo que a rodeia, em especial após sua internação no hospício. A insanidade da protagonista demarca sua entrada em um território caracterizado por uma nova ordem simbólica, avessa à lógica humana carnivorista.

Após assumir o papel de figurante em um vídeo gravado pelo seu cunhado, na segunda narrativa ("A mancha mongólica"), Yonghye Kim faz sexo com o cunhado, que os filma. Inhye Kim (irmã mais velha de Yonghye) descobre o vídeo, chama uma ambulância e encaminha tanto a irmã quanto o cunhado traidor para uma instituição psiquiátrica, alegando insanidade da parte dos dois. Não deixa de ser curioso que tanto o casamento de Jeong e Yonghye quanto o casamento do videoartista e Inhye são desfeitos em função da "leitura" dos comportamentos de Yonghye como "insanos". Todavia, ao longo da terceira narrativa, Inhye Kim volta a se aproximar da irmã, testemunhando as violências a que essa é submetida no sanatório por ocasião da alimentação forçada. Yonghye Kim apresenta cada vez mais problemas alimentares, recusando-se a comer (sendo diagnosticada com anorexia nervosa, na terceira narrativa) e alegando alimentar-se apenas de água e luz solar.

Diante dos apelos insistentes da irmã para que coma, para não morrer de inanição, Yeongye pergunta: "e por que não posso morrer?" (Han KANG, 2018, p. 148). A violência dos enfermeiros do sanatório, na ocasião em que a forçam a comer (com a introdução de uma sonda de alimentação) contra a vontade de Yonghye Kim é análoga à violência sofrida pela protagonista à violência do pai, na cena em ele tenta obrigá-la a comer carne de porco (KANG, 2018, p. 164-165). No universo construído por Han Kang, não resta às mulheres sequer a liberdade de decisão com relação ao que comem. Nesse sentido, a anorexia da protagonista pode ser lida como um ato de resistência simbólica e não violenta às violências e às arbitrariedades do masculinismo na sociedade coreana.

Vale ressaltar que, ao longo das três narrativas, o sexo nunca é visto como fonte de prazer pelas mulheres. Em algumas das cenas, elas simplesmente mostram-se inertes e indiferentes ao intercurso sexual com seus parceiros; em outros momentos, mesmo que se mostrando visivelmente indispostas e recusando-se ao ato, elas são forçadas ao sexo com seus companheiros (particularmente com seus maridos). Há uma visível ausência de sexo consentido por parte das irmãs Kim nas relações que travam com seus maridos e/ou amantes. Ainda que correndo os riscos de um trocadilho crítico, poder-se-ia dizer que $A$ vegetariana não é um romance sobre vegetarianismo ou sobre veganismo, mas sim sobre os apetites masculinos: pela carne dos animais nos pratos, e pela carne das mulheres na cama (Cf. Carol ADAMS, 2012) ${ }^{4}$. Indo um pouco mais além, mas sem nunca se afastar daquilo que é possível de ser enunciado pelo próprio universo diegético construído pelas três narrativas de Han Kang, pode-se afirmar que $A$ vegetariana é, antes de qualquer coisa, um ato de resistência não violenta e, simultaneamente, uma alegoria

\footnotetext{
${ }^{4}$ Torna-se aqui bastante evidente a proximidade do projeto narrativo de Han Kang com o projeto teórico/político de
} um feminismo vegano apresentado por Carol Adams em A política sexual da carne. 
política da falta de liberdade de escolha das mulheres. Mesmo quando essa liberdade de escolha refere-se àquilo que as mulheres querem comer ou deixar de comer.

\section{Referências}

ADAMS, Carol. A política sexual da carne: a relação entre carnivorismo e a dominância masculina. São Paulo: Alaúde Editorial, 2012.

BAL, Mieke. "Scared to death". In: BAL, Mieke; BOER, Inge E. The point of theory: practices of cultural analysis. New York: Continuum, 1994. p. 32-47.

BAL, Mieke. "First person, second person, same person". In: BAL, Mieke. Double exposures: the subject of cultural analysis. London: Routledge, 1996. p. 165-194.

BAL, Mieke. "Afterword: theses on the use of narratology for cultural analysis. In: Narratology: introduction to the theory of narrative". 2nd ed. Toronto: University of Toronto Press, 1997. p. 220-228.

KANG, Han. A vegetariana. Trad. de Jae Hyung Woo. São Paulo: Todavia, 2018.

Anselmo Peres Alós (anselmoperesalos@gmail.com) é doutor em Letras (2007) pela UFRGS, realizou estágio pós-doutoral na UFPE, como bolsista PNPD/CAPES. Foi Professor-Leitor junto ao Instituto Superior de Ciência e Tecnologia de Moçambique (ISCTEM), em Maputo, no período de 2009 a 2011. É Líder do Grupo de Pesquisa Trânsitos teóricos e des/ocamentos epistêmicos: feminismos, estudos de gênero e teoria queer. Membro da ANPOLL desde 2017, e da ANPOF desde 2018. Membro da ABRALIC desde 2004. Autor dos livros A letra, o corpo e o desejo (2013) e Leituras a contrapelo da narrativa brasileira (2017). Organizador de Poéticas da masculinidade em ruínas: o amor em tempos de AIDS (2017).

\section{COMO CITAR ESSE ARTIGO DE ACORDO COM AS NORMAS DA REVISTA}

ALÓS, Anselmo Peres. "Veganismo, violência sexual e insanidade na narrativa coreana contemporânea". Revista Estudos Feministas, Florianópolis, v. 29, n. 1, e72810, 2021.

\section{CONTRIBUIÇÃO DE AUTORIA}

Não se aplica.

\section{FINANCIAMENTO}

CNPq (Bolsa de Produtividade em Pesquisa - Categoria PQ-2).

\section{CONSENTIMENTO DE USO DE IMAGEM}

Não se aplica.

APROVAÇÃO DE COMITÊ DE ÉTICA EM PESQUISA

Não se aplica.

CONFLITO DE INTERESSES

Não se aplica.

LICENÇA DE USO

Este artigo está licenciado sob a Licença Creative Commons CC-BY International. Com essa licença você pode compartilhar, adaptar, criar para qualquer fim, desde que atribua a autoria da obra.

\section{HISTÓRICO}

Recebida em 07/04/2020

Aprovada em 25/05/2020 